\title{
Determining factors of renal dysfunction during cisplatin chemotherapy
}

\author{
SORIN SĂFTESCU ${ }^{1}$, DOREL POPOVICI ${ }^{1}$, CRISTINA OPREAN $^{2}$, ALINA NEGRU $^{3}$, ANITA HAIDUC $^{4}$, \\ SIMONA STANCA ${ }^{5}$, DANIEL-CLAUDIU MALIȚA ${ }^{6}$, SIMONA VOLOVĂȚ $^{7}$ and ȘERBAN NEGRU ${ }^{1}$

\begin{abstract}
Departments of ${ }^{1}$ Oncology, ${ }^{2} \mathrm{PhD}$ Program, Department of Pathology, ${ }^{3}$ Department of Cardiology and ${ }^{4} \mathrm{PhD}$ Program, Department of Ophthalmology, 'Victor Babeș' University of Medicine and Pharmacy, 300041 Timisoara; ${ }^{5}$ Department of Pediatrics, 'Carol Davila' University of Medicine and Pharmacy, 050474 Bucharest;

${ }^{6}$ Department of Radiology and Medical Imaging, 'Victor Babeș’ University of Medicine and Pharmacy, 300041 Timisoara;

${ }^{7}$ Department of Oncology, 'Gr. T. Popa' University of Medicine and Pharmacy, 700115 Iasi, Romania
\end{abstract}

Received September 9, 2020; Accepted October 9, 2020

DOI: $10.3892 / \mathrm{etm} .2020 .9516$

\begin{abstract}
Cisplatin remains one of the most active antineoplastic treatments used in oncology, being the most prestigious exponent of the golden age in chemotherapy at the end of the 20 th century. This chemotherapeutic drug is used for curative or palliative treatments in testicular, ovarian, head and neck neoplasms, sarcomas and lymphomas. The limiting dose adverse effect of cisplatin is nephrotoxicity. The present study aimed to evaluate the magnitude of the damage to renal function and to identify the risk or protective factors in renal toxicity. The retrospective study was performed using 81 consecutive patients who underwent at least three cycles of cisplatin chemotherapy. The results indicate an average decline in glomerular filtration rate (GFR) of $9 \mathrm{ml} / \mathrm{min}$. Women appear to be less by a decline in renal function (a relative decline of GFR of $-5 \%$ for women compared to $-9 \%$ for men). The decline in GFR was found to be proportional to age; overweight (not obese) individuals had the best renal function behavior under cisplatin treatment, while the association of anaemia appears to be a risk factor for renal toxicity. The use of cisplatin in oncology in the last years may have decreased, either by using combination chemotherapy instead of monotherapy, or by its displacement by newly discovered treatments (e.g., immunotherapy in lung cancer). Therefore, it is possible that the profile of patients who are exposed to this drug and the duration of exposure have been modified compared to previous studies.
\end{abstract}

Correspondence to: Dr Dorel Popovici, Department of Oncology, 'Victor Babeș' University of Medicine and Pharmacy, P-ta Eftimie Murgu nr. 2, 300041 Timisoara, Romania

E-ail: dorelpopovici@gmail.com

Key words: cisplatin, renal toxicity, chemotherapy, glomerular filtration rate, anaemia
The objectives of the present study were to assess the magnitude of the renal function damage during cisplatin treatment and to identify the risk and the protective factors in term of renal toxicity.

\section{Introduction}

Cisplatin (cis-diaminedichloroplatinum II, CDDP), also known as Peyrone's salt, was discovered as a substance in 1844, 100 years before its first use as a cytostatic drug. Its chemical structure was discovered in 1893 by Alfred Werner. In 1965 , one property of the salts resulting from platinum electrolysis was accidentally discovered to inhibit bacterial division without, however, a bactericidal effect, which resulted in the formation of 300 times longer than usual bacterial filaments. It is to be noted that the trans isomer does not maintain these properties. The chemical formula of the active form is the hydrolyzed $c i s-\left[\mathrm{PtCl}\left(\mathrm{NH}_{3}\right)_{2}\left(\mathrm{H}_{2} \mathrm{O}\right)\right]^{+}(1)$. It was approved for use in 1978 for testicular cancer; its introduction increased the cure rate from 10 to $85 \%$ (2).

According to the Summary of Product Characteristics, the current indications for cisplatin treatment alone or in combination chemotherapy, in curative or palliative treatments are testicular carcinoma, ovarian carcinoma (stages III and IV) and squamous cell epithelium of the head and neck (palliative therapy), sarcomas and lymphomas. Its efficiency has been also observed in cases of lung carcinoma, bladder cancer, cervical tumors $(3,4)$. The dosages may increase up to $120 \mathrm{mg} / \mathrm{m}^{2}$ body surface, with administration cycles every three or four weeks (5).

The mechanism of action is the inhibition of DNA synthesis by creating cross-links between and within the DNA strands (the preferred binding site is N-7 position of guanine and adenosine). To a lesser extent, RNA synthesis and protein synthesis are inhibited. DNA alterations induce cell apoptosis. Immunogenic effects (by increasing the tumor antigenicity) were observed, as well as immunosuppressive and radiosensitizing effects. 
Concerning pharmacokinetics, cisplatin binds relatively irreversibly to plasma proteins (over 90\%), and the bond amount does not exert antineoplastic effects. There is an initial $t^{1} / 2$ (by distribution) of $10-60 \mathrm{~min}$ and a terminal $\mathrm{t}^{1} / 2$ (by elimination) of 2-5 days. Within five days, no more than $45 \%$ of the administered quantity is excreted. Fecal excretion is minimal (6).

The most frequent adverse effects are nephrotoxicity, ototoxicity, neuropathy, spinal toxicity, allergic phenomena, a potential carcinogen (late risk of leukemia). The occurrence of chromosomal aberrations in cultured animal cells has been noted. The drug includes special warnings regarding dose-dependent, cumulative and potentially severe renal toxicity (manifesting in 30-40\% of the patients); the nephrotoxic potential is additive with other nephrotoxic agents (for example aminoglycosides, contrast agents and ifosfamide). Cisplatin toxicity is also potentiated by co-administration of diuretics (furosemide) and beta-blockers (propranolol). For this reason, it is not advisable to force diuresis with furosemide during the administration of cisplatin treatment, although higher diuresis has a protective effect. Nephrotoxicity is the dose-limiting effect of cisplatin treatment.

Additionally, nausea and associated emesis potential (an effect that can extend up to 7 days after administration) have been noted. Cisplatin is one of the most emetogenic substances used in oncology.

Other side effects are neurotoxicity and cumulative ototoxicity (also potentiated by other ototoxic substances: furosemide and aminoglycosides). The mechanism of ototoxicity may be related to the non-competitive binding (but potentially reversible) at the level of the mechanosensitive transmembrane transporter $\mathrm{Na}^{+} / \mathrm{H}^{+}$(3); mutagenicity potential and fertility reduction (all chemotherapies carry a restriction of conception during the administration and for 6 months after the end of treatment, for both sexes). It is contraindicated during pregnancy. It is teratogenic and mutagenic for laboratory animals; hyponatremia, hypokalemia, hypomagnesemia and hypocalcemia may occur during cisplatin treatment; cardiac arrhythmias and pyrexia (very common).

Cisplatin exerts influence on other chemotherapies: Paclitaxel clearance is reduced by $33 \%$. Overdose can be lethal, and there is no specific antidote.

Calcitriol appears to potentiate the antiproliferative effect of cisplatin. In addition, cisplatin appears to exert oxidative phosphorylation decoupling effects (7).

With regard to renal toxicity, the kidneys accumulate more cisplatin than other tissues, being the main route of elimination (glomerular filtration and tubular secretion). The concentration achieved in the proximal contorted tube is five times higher than the plasmatic one. This phenomenon probably explains the nephrotoxic characteristics of cisplatin (7).

Current strategies used to prevent nephrotoxicity and acute kidney injury are hydration, magnesium supplementation (8-16 mEq) and mannitol-induced diuresis (osmotic diuresis) (8). The second most important platinum derivative used in oncology is carboplatin, for which nephrotoxicity is not so expressed, although it has the disadvantage of more severe myelosuppression. Moreover, carboplatin has a much higher $t^{1} / 2(30 \mathrm{~h})$, and for similar antitumor effects, dosages are in the ratio of $4: 1$ (carboplatin:cisplatin).
Acute kidney injury associated with cisplatin administration is more common in men, and it occurs with urinary loss of sodium, magnesium and decreased urine concentration. Organic cation transporter 2 (OCT2) is involved in CDDP nephrotoxicity. Hypomagnesemia increases OCT2 expression in the proximal contort tube and increases CDDP uptake, a reason for additional magnesium intake to prevent toxicity. It has been also found that cimetidine would exert protective effects on CDDP by decreasing the expression of the copper transporter 1 (Ctr-1) (9).

The pathophysiological mechanisms involved in CDDP nephrotoxicity are: tubular toxicity, vascular lesions (vasoconstriction), glomerular lesions andinterstitial injury (secondary to an inflammatory response) (10).

Acute kidney injury is defined as an increase of at least $25 \%$ in the creatinine value relative to the baseline value within 30 days of cisplatin administration. A study of 821 adults who survived at least 5 years after treatment with CDDP revealed the presence of acute kidney injury in 31.5\% of patients with a median GFR decline estimated at $10 \mathrm{ml} / 1.73 \mathrm{~m}^{2}$ BSA. GFR decreases at values $<29 \mathrm{ml} / \mathrm{min}$ were found to occur in only $3 \%$ of the patients, without dialysis during follow-up. The incidence of acute kidney injury was double in the segment $>66$ years of age compared to the segment 45-65 years. Most patients suffered from small, but permanent reductions in estimated GFR (11).

\section{Patients and methods}

Patients and treatment. The study was approved by the Oncohelp Clinic Ethics Committee; all 163 patients included in the study have voluntarily agreed to participate and provided written consents. One hundred and sixty-three chemotherapy initiations containing cisplatin in the period December 18, 2018 to February 19, 2020 (107 men and 56 women) with 436 treatment cycles (276 in men and 160 in women) were identified retrospectively in the records of OncoHelp Oncology Center. The mean age of the patients at the initiation of treatment was 56.88 years (55.48 for the subgroup of men and 59.29 for the subgroup of women).

The data were processed after anonymization. We carried out the correlation between the biometric data [height, weight and body mass index (BMI)] and the paraclinical data (complete blood count and blood biochemistry) at the patients' hospital admission and during the chemotherapy administration; their treatment endurance being also tracked (number of chemotherapy cycles per patient).

For data processing, we chose individuals who had undergone at least three cycles of cisplatin treatment ( 81 cases and 243 administrations). The biometric and biological data from the evaluation for cycle $1(\mathrm{Cl})$ treatment and the evaluation before $\mathrm{C} 3$ treatment (after two administrations) were compared. The glomerular filtration rate was estimated using the Cockcroft-Gault formula (12).

Statistical analysis. For statistical evaluations, $\mathrm{P}<0.05$ was considered a significance threshold upon applying t-test and paired t test (available online https://www.medcalc.org/calc/ comparison_of_means.php and https: //www.statskingdom respectively. com / 160MeanT2pair.html). 
Table I. Treatment cycles administered and the number of patients treated.

\begin{tabular}{lcccccccc}
\hline Chemo cycle & 1 & 2 & 3 & 4 & 5 & 6 & 7 \\
\hline Number of cisplatin administrations & 163 & 110 & 81 & 52 & 17 & 11 & 1 \\
\hline
\end{tabular}

Table II. Table II. Evolution of the average creatinine levels ( $\mathrm{mg} / \mathrm{dl})$ during the entire cycle 1-3.

\begin{tabular}{lcccc}
\hline Chemo cycle & 1 & 2 & 3 & C3 vs. C1 \% \\
\hline Medium creatininemia & 0.75 & 0.83 & 0.81 & 8 \\
Male & 0.78 & 0.87 & 0.85 & 9 \\
Female & 0.71 & 0.76 & 0.75 & 6 \\
\hline
\end{tabular}

Table III. Evolution of the glomerular filtration rate $(\mathrm{ml} / \mathrm{min})$ by treatment cycle and sex.

\begin{tabular}{lrrcc}
\hline Chemo cycle & 1 & 2 & 3 & $\Delta \mathrm{C} 3$ vs.C1\% \\
\hline Medium GFR & 110 & 102 & 101 & -8 \\
Medium GFR, male & 117 & 107 & 106 & -9 \\
Medium GFR, female & 96 & 91 & 91 & -5 \\
\hline
\end{tabular}

Table IV. Evolution of GFR ( $\mathrm{ml} / \mathrm{min})$ by treatment cycles and age groups.

\begin{tabular}{lrrrc}
\hline Chemo cycle & 1 & 2 & 3 & $\Delta \mathrm{C} 3$ vs. C1 \% \\
\hline$<50$ years & 125 & 119 & 119 & -5 \\
$50-64$ years & 113 & 105 & 104 & -8 \\
$\geq 65$ years & 89 & 77 & 76 & -15 \\
\hline
\end{tabular}

GFR, glomerular filtration rate.

Table V. Evolution of GFR ( $\mathrm{ml} / \mathrm{min})$ in the first three cycles of administration according to BMI $\left(\mathrm{kg} / \mathrm{m}^{2}\right)$.

\begin{tabular}{lrrrc}
\hline Chemo cycle & \multicolumn{1}{c}{1} & \multicolumn{1}{c}{2} & 3 & $\Delta$ C3 vs. C1 \% \\
\hline BMI $<25$ & 95 & 85 & 86 & -9 \\
BMI $=25-29$ & 113 & 110 & 110 & -3 \\
BMI $\geq 30$ & 136 & 118 & 117 & -14 \\
\hline
\end{tabular}

GFR, glomerular filtration rate; BMI, body mass index.

\section{Results}

The number of treatment cycles undergoing each patient was found to vary. Some patients ceased the treatment because of various reasons, either due to the disease progression or due
Table VI. Evolution of GFR ( $\mathrm{ml} / \mathrm{min})$ in the first three cycles of administration depending on the presence of anemia.

\begin{tabular}{lcrrc}
\hline Chemo cycle & 1 & 2 & 3 & $\Delta \mathrm{C} 3$ vs. C1 \% \\
\hline Anemia $\mathrm{Hb}<12$ & 105 & 92 & 92 & -12 \\
No anemia $\mathrm{Hb} \geq 12$ & 112 & 106 & 105 & -6 \\
\hline
\end{tabular}

GFR, glomerular filtration rate; $\mathrm{Hb}$, hemoglobin.

Table VII. Evolution of GFR ( $\mathrm{ml} / \mathrm{min})$ in the first three cycles of administration according to the mean red blood cell volume $(\mathrm{MCV}, \mathrm{fL})$ at the time of initiation.

\begin{tabular}{lrrrc}
\hline Chemo cycle & 1 & 2 & 3 & $\Delta$ C3 vs. C1\% \\
\hline MCV $<90$ & 114 & 105 & 104 & -9 \\
MCV $\geq 90$ & 93 & 87 & 88 & -5 \\
\hline
\end{tabular}

GFR, glomerular filtration rate.

Table VIII. Evolution of GFR ( $\mathrm{ml} / \mathrm{min}$ ) in the first three cycles of administration according to AST (IU/1) value at the time of initiation.

\begin{tabular}{lcccc}
\hline Chemo cycle & 1 & 2 & 3 & $\Delta \mathrm{C} 3$ vs. C1 \% \\
\hline AST $<18$ & 114 & 103 & 100 & -12 \\
AST $\geq 18$ & 109 & 101 & 102 & -6 \\
\hline
\end{tabular}

GFR, glomerular filtration rate; AST, aspartate transaminase.

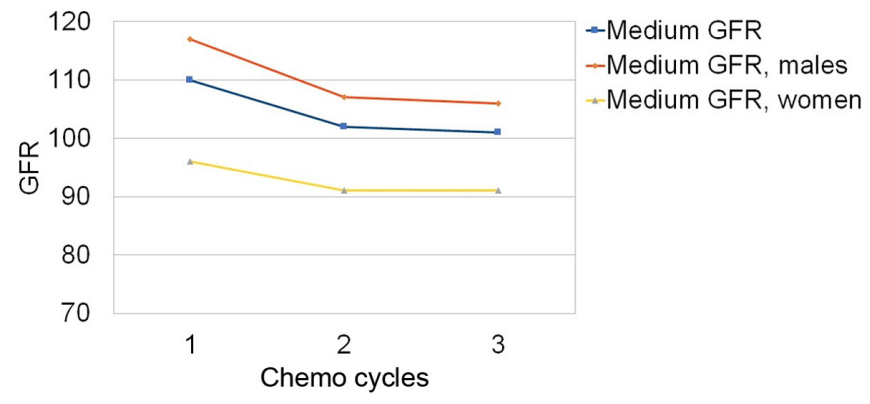

Figure 1. Evolution of the glomerular filtration rate $(\mathrm{ml} / \mathrm{min})$ by treatment cycles and sex. GFR, glomerular filtration rate.

to their toxicity intolerance. The average number of treatment cycles was 1.72 for men and 2.85 for women and there was 
Table IX. Profile of patients who suffered the greatest reductions in GFR (9 $\mathrm{ml} / \mathrm{min})$.

\begin{tabular}{|c|c|c|c|c|c|c|c|c|c|c|c|}
\hline Sex & Age & GFR at $\mathrm{C} 1$ & GFR at C3 & GFR \% & $\mathrm{kg} \mathrm{C} 1$ & $\mathrm{~kg} \mathrm{C} 3$ & $\mathrm{~kg} \%$ & $\mathrm{Hb} \mathrm{C1}$ & $\mathrm{Hb} \mathrm{C} 3$ & $\mathrm{Hb} \%$ & Type of cancer \\
\hline M & 68 & 164 & 98 & -40 & 105 & 105 & 0 & 8.7 & 10.4 & 20 & Lung \\
\hline $\mathrm{F}$ & 61 & 122 & 76 & -38 & 55 & 54 & -2 & 12.1 & 12 & -1 & Colorectal \\
\hline $\mathrm{F}$ & 71 & 65 & 40 & -38 & 53 & 53 & 0 & 13.8 & 11.5 & -17 & Esophageal \\
\hline M & 62 & 172 & 108 & -37 & 89 & 60 & -33 & 8.2 & 10.3 & 26 & Lung \\
\hline $\mathrm{F}$ & 63 & 112 & 71 & -37 & 75 & 70 & -7 & 14.1 & 10.8 & -23 & Bladder \\
\hline M & 73 & 76 & 49 & -36 & 79 & 78 & -1 & 11.3 & 9.9 & -12 & ENT \\
\hline M & 48 & 108 & 70 & -35 & 61 & 55 & -10 & 14 & 10.1 & -28 & Gastric \\
\hline $\mathrm{F}$ & 50 & 124 & 82 & -34 & 69 & 69 & 0 & 8.8 & 11.3 & 28 & Lung \\
\hline M & 57 & 183 & 123 & -33 & 92 & 80 & -13 & 15.1 & 11.8 & -22 & Lung \\
\hline M & 62 & 145 & 97 & -33 & 106 & 101 & -5 & 15.2 & 12.3 & -19 & Lung \\
\hline M & 64 & 211 & 144 & -32 & 130 & 130 & 0 & 13.6 & 11.9 & -13 & Lung \\
\hline M & 64 & 117 & 79 & -32 & 42 & 53 & 26 & 8.2 & 8.5 & 4 & Esophageal \\
\hline M & 65 & 73 & 50 & -32 & 57 & 55 & -4 & 11.6 & 8.3 & -28 & Esophageal \\
\hline $\mathrm{F}$ & 46 & 132 & 90 & -32 & 70 & 70 & 0 & 13.9 & 10.3 & -26 & Cervical \\
\hline M & 50 & 137 & 97 & -29 & 67 & 67 & 0 & 14.2 & 12.4 & -13 & Gastric \\
\hline M & 69 & 131 & 93 & -29 & 69 & 65 & -6 & 10.7 & 10.6 & -1 & Pancreatic \\
\hline M & 62 & 124 & 92 & -26 & 108 & 108 & 0 & 15.2 & 13.4 & -12 & Lung \\
\hline
\end{tabular}

Age is expressed in years. M, male; F, female; GFR, glomerular filtration rate; $\mathrm{Hb}$, hemoglobin.

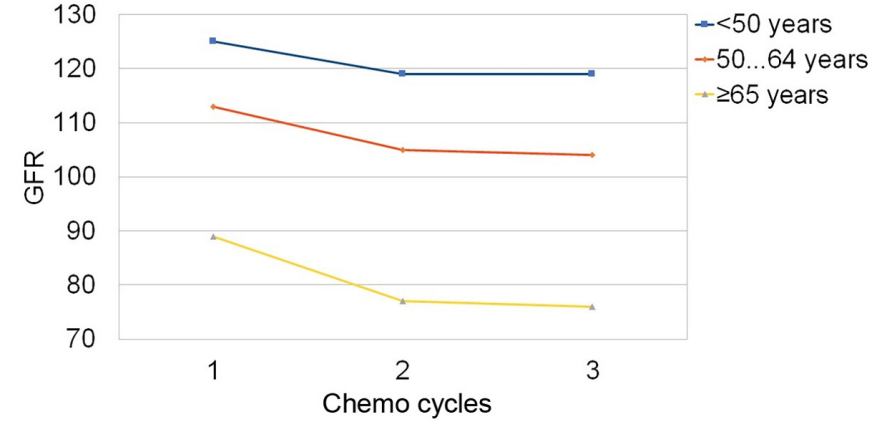

Figure 2. Evolution of GFR ( $\mathrm{ml} / \mathrm{min})$ by treatment cycle and age group. GFR, glomerular filtration rate.

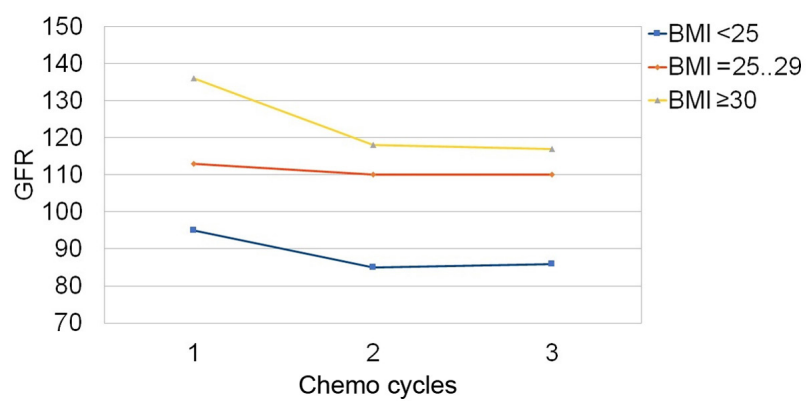

Figure 3. Evolution of GFR ( $\mathrm{ml} / \mathrm{min})$ in the first three cycles of administration according to BMI $\left(\mathrm{kg} / \mathrm{m}^{2}\right)$. GFR, glomerular filtration rate; BMI, BMI, body mass index.

a sharp decrease in patient number from one chemo cycle to another (Table I).

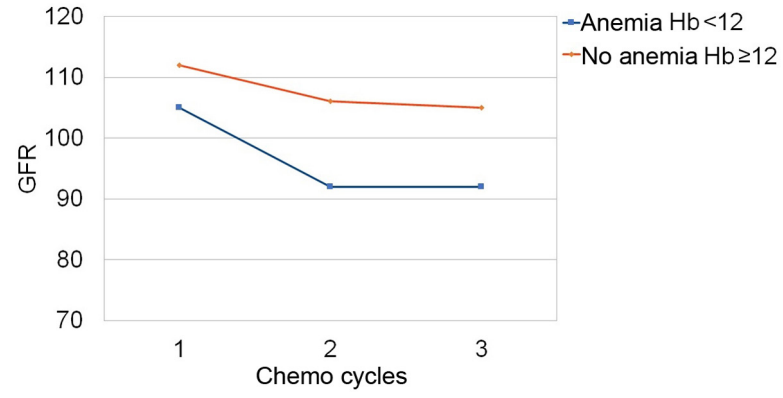

Figure 4. Evolution of GFR ( $\mathrm{ml} / \mathrm{min})$ in the first three cycles of administration depending on the presence of anemia. GFR, glomerular filtration rate.

The mean creatinine value at initiation was higher for men and its relative increase until entry into treatment cycle 3 was also higher for men (Table II).

The mean GFR was higher for men at the time of treatment initiation, but renal function suffered less during treatment for female patients (Table III and Fig. 1).

It was observed that young people had the lowest functional renal damage following treatment, while for people $>65$ years the renal functional loss was significant (Table IV and Fig. 2).

Unexpectedly, overweight patients (BMI between 25 and 30) had the best behavior in terms of renal function (Table V and Fig. 3).

The presence of anemia was associated with a greater decline of GFR (Table VI and Fig. 4).

Higher medium corpuscular volume (MCV) seemed associated with less GFR loss (Table VII).

A low value (>18 U/l) for aspartate aminotransferase (AST, enzyme also present in the kidneys) was associated with a higher risk of damage to the renal function (Table VIII). 
Significant weight loss and significant hemoglobin loss were often associated with cases of marked decreases in GFR (Table IX).

\section{Discussion}

The average number of treatment cycles administered per patient could have been higher in the case of a longer follow-up (some of the treatments initiated were ongoing at the time of data collection), but their proportion was not extremely high given the ratio of the average treatment duration of 8 weeks and the duration of the follow-up of 60 weeks. Conversely, chemotherapy with cisplatin is 'well known' for its poor tolerability, being listed among the most emetic chemotherapeutic drugs (13).

Women appeared to be somehow protected from the decline in renal function (cisplatin dosing only takes into account creatinine or GFR as an on-off condition). The decline of GFR was found to be proportional to patient age. Special attention should be paid to the age group over 65 years.

Overweight patients (not obese) had the best GFR behavior for cisplatin aggression. Systematic review performed by other authors for cisplatin dosage revealed actual body weight utilization as most frequent used weight input (14) and this was also the case in our chemotherapy dose calculation.

The association of anemia is a risk factor for a steeper decline of GFR. An MCV in the upper normal area is associated with a lower starting GFR, although it appears to be a renoprotective factor, meaning that the relative GFR loss is less important. Animal models indicated cisplatin-induced anemia as a persistent condition (many weeks) and unaccompanied by expected EPO response (15).

From a statistical point of view, the volume of available patients for whom there were complete data on cycles 1,2 and 3 of cisplatin administration allowed the following statistical validations through a pair-t-test that shows the levels of significance $\mathrm{P}<0.05$ reached for decreases of GFR from cycle 1 to cycle 3 (evaluations after $\mathrm{C} 1$ and $\mathrm{C} 2$, before the administration of $\mathrm{C} 3)(\mathrm{P}=0.00059$, mean variation of $\mathrm{GFR}=-9 \mathrm{ml} / \mathrm{min}$, standard deviation of variation $=22.82$, cases $=82$ ).

In addition, a value of $\mathrm{P}=0.00562$ was calculated for the decrease of GFR from $\mathrm{C} 1$ to $\mathrm{C} 3$ in cases over 65 years $(\mathrm{P}=0.00562$, mean variation of $\mathrm{GFR}=-13 \mathrm{ml} / \mathrm{min}$, standard deviation of variation $=18.03$, cases $=19$ ). Authors investigating elderly and non-elderly patients treated with cisplatin did not demonstrate differences in pharmacokinetics (clearance and volume of distribution) for the age criteria (16).

The t-test performed for the differences observed at $\mathrm{C} 3$ reached significance levels $\mathrm{P}<0.05$ for the patients group $<50$ years old vs. group $>65$ years $[\mathrm{P}=0.0011 ; \mathrm{GFR}=118.9$ vs . $75.7 \mathrm{ml} / \mathrm{min}$, standard error (STD) $=46$ vs. $26, \mathrm{~N}=19$ vs. 19$]$.

The patients group with BMI $<25$ vs. BMI group $=25-29$ reached statistical significance $(\mathrm{P}=0.0049 ; \mathrm{GFR}=85.8$ vs. $110.1 \mathrm{ml} / \mathrm{min}, \mathrm{STD}=27.3$ vs. $35, \mathrm{~N}=32$ vs. 24$)$.

In addition, the female group vs. the male group demonstrated statistical significance $(\mathrm{P}=0.0453$ creatinine $=0.749$ vs . $0.848 \mathrm{mg} / \mathrm{dl}, \mathrm{STD}=0.16$ vs. $0.23, \mathrm{~N}=28$ vs. 54 ). ( $\mathrm{NB}$ validation performed for GFR revealed $\mathrm{P}=0.10$ ).

After two cisplatin administrations (evaluation made before the third administration), the mean relative decrease of GFR was $8 \%(-9.0 \mathrm{ml} / \mathrm{min})$, that is, from a pre-therapeutic mean of $110.06 \mathrm{ml} / \mathrm{min}$ before initiation to $101.02 \mathrm{ml} / \mathrm{min}$ before cycle three (average relative decrease of GFR of $-9 \%$ for men and $-5 \%$ for women).

Protective factors associated with lower GFR decline were observed in the following categories of patients: Overweight (-3\% relative GFR decline), female (-5\% relative GFR decline), aged $>50$ years $(-5 \%)$, absence of anemia $(-6 \%)$. Factors associated with higher GFR losses were observed in the following categories of patients: Age $>65$ years $(-15 \%$ relative decline in GFR), obesity (-14\%), presence of anemia and AST values $<18$ $(-12 \%)$, male sex $(-9 \%)$. The recorded decreases for the GFR were statistically significant for the group as a whole, especially for the patients $>65$ years. The following factors were correlated with lower GFR: Age $>65$ years and BMI group $<25$ for evaluation performed prior to cycle three.

\section{Acknowledgements}

Professional editing, linguistic and technical assistance was performed by Irina Radu, Individual Service Provider.

\section{Funding}

No funding was received.

\section{Availability of data and materials}

All data and materials supporting the results of the present study are available in the published article.

\section{Authors' contributions}

SoS, DP and CO conceived the research concept of the study. All authors developed the theory and performed the computation procedures. AN and AH verified the analytical methods of the study. SoS, SiS and DM helped supervise the project and verified the accuracy of the data. SV and SN contributed to the interpretation of the intermediate and final results. SoS took the lead in writing the manuscript. All authors provided critical feedback and helped shape the data, analysis, and redacted the conclusions of the study. All authors read and approved the final manuscript.

\section{Ethics approval and consent to participate}

Not applicable.

\section{Patient consent for publication}

Not applicable.

\section{Competing interests}

The authors declare that they have no competing interests.

\section{Authors' information}

Anita Haiduc is a PhD Student at the 'Victor Babes' University of Medicine and Pharmacy, Timisoara, Romania. 


\section{References}

1. Rosenberg B, Vancamp L and Krigas T: Inhibition of cell division in Escherichia coli by electrolysis products from a platinum electrode. Nature 205: 698-699, 1965.

2. Einhorn LH: Treatment of testicular cancer: A new and improved model. J Clin Oncol 8: 1777-1781, 1990.

3. FDA Cisplatin label. https://www.accessdata.fda.gov/drugsatfda_docs/label/2011/018057s080lbl.pdf accessed Oct 102020

4. Brown A, Kumar S and Tchounwou PB: Cisplatin-based chemotherapy of human cancers. J Cancer Sci Ther 11: 97, 2019. Epub 2019 Apr 8. PMID: 32148661; PMCID: PMC7059781.

5. Electronic medicines compendium (emc). https://www.medicines.org.uk/emc/medicine/623\#INDICATIONS accessed Oct 102020.

6. Milosavljevic N, Duranton C, Djerbi N, Puech PN, Gounon P, Lagadic Gossmann D, Dimanche Boitrel MT, Rauch C, Tauc M, Counillon L, et al: Nongenomic effects of cisplatin: Acute inhibition of mechanosensitive transporters and channels without actin remodelling. Cancer Res 70: 7514 7522, 2010.

7. Dasari S and Tchounwou PB: Cisplatin in cancer therapy: Molecular mechanisms of action. Eur J Pharmacol 740: 364 378, 2014.

8. Crona DJ, Faso A, Nishijima TF, McGraw KA, Galsky MD and Milowsky MI: A systematic review of strategies to prevent cisplatin induced nephrotoxicity. Oncologist 22: 609 619, 2017. https://doi.org/10.1634/theoncologist.2016-0319.

9. Volarevic V, Djokovic B, Jankovic MG, Harrell CR, Fellabaum $\mathrm{C}$, Djonov V and Arsenijevic N: Molecular mechanisms of cisplatin-induced nephrotoxicity: A balance on the knife edge between renoprotection and tumor toxicity. J Biomed Sci 26: 25 , 2019.
10. Pabla N and Dong Z: Cisplatin nephrotoxicity: Mechanisms and renoprotective strategies. Kidney Int 73: 994 1007, 2008.

11. Latcha S, Jaimes EA, Patil S, Glezerman IG, Mehta S and Flombaum CD: Long term renal outcomes after cisplatin treat $\neg$ ment. Clin J Am Soc Nephrol 11: 1173 1179, 2016.

12. Cockcroft DW and Gault MH: Prediction of creatinine clearance from serum creatinine. Nephron 16: 31-41, 1976.

13. Ryan JL: Treatment of chemotherapy induced nausea in cancer patients. Eur Oncol 6: 14 16, 2010. https://doi.org/10.17925/ EOH.2010.06.02.14

14. Casas A, Torroba B, Tapia B and Garcia-Del-Barrio MA: 4CPS- 114 dosing of platinum and taxanes in obese patients: A systematic review. Eur J Hosp Pharm Sci Pract 26: A121, 2019.

15. Wood PA and Hrushesky WJ: Cisplatin-associated anemia: An erythropoietin deficiency syndrome. J Clin Invest 95: 1650-1659, 1995.

16. Minami H, Ohe Y, Niho S, Goto K, Ohmatsu H, Kubota K, Kakinuma R, Nishiwaki Y, Nokihara H, Sekine I, et al: Comparison of pharmacokinetics and pharmacodynamics of docetaxel and Cisplatin in elderly and non-elderly patients: Why is toxicity increased in elderly patients? J Clin Oncol 22: 29012908, 2004

This work is licensed under a Creative Commons Attribution-NonCommercial-NoDerivatives 4.0 International (CC BY-NC-ND 4.0) License. 